\title{
Análise de efetividade das políticas públicas de Arranjo Produtivo Local para o desenvolvimento local a partir da teoria institucional
}

\author{
Márcio Jacometti \\ Universidade Tecnológica Federal do Paraná / Programa de Pós-Graduação em Administração \\ Curitiba / PR - Brasil \\ Marcos de Castro \\ Universidade Estadual do Centro-Oeste / Programa de Mestrado Profissional em Administração \\ Guarapuava / PR - Brasil \\ Sandro Aparecido Gonçalves \\ Instituto Brasileiro de Estudos e Pesquisas Sociais \\ Curitiba / PR - Brasil \\ Mayla Cristina Costa \\ Universidade Federal do Paraná / Programa de Pós-Graduação em Contabilidade \\ Curitiba / PR - Brasil
}

\begin{abstract}
O objetivo da pesquisa foi identificar como as políticas públicas explicam o acentuado desenvolvimento econômico do Arranjo Produtivo Local (APL) de móveis de Arapongas (PR), no período de 2000 a 2012, com base na perspectiva institucional de análise. Utilizou-se o estudo de caso com métodos qualitativos e quantitativos. A fase qualitativa foi baseada na análise de conteúdo temática de documentos, realizada em 2012, que subsidiou a elaboração do questionário estruturado aplicado em 2013 junto a 38 empresas do APL. As condições do ambiente institucional alteraram o ambiente técnico no sentido de permitir a sustentação do padrão de desenvolvimento observado, mas ficaram muito aquém da expectativa para a melhoria de competitividade e benefícios econômicos esperados para empresas segundo um modelo de APL disseminado, tendo em vista limitações nas relações sociais, frágeis para proporcionar confiança entre os atores locais e reduzir o isolamento em pequenos grupos e concorrência individual.
\end{abstract}

Palavras-chave: políticas públicas; desenvolvimento econômico; contexto institucional; relações sociais.

DOI: http://dx.doi.org/10.1590/0034-7612142712

Artigo recebido em 11 nov. 2014 e aceito em 20 abr. 2016. 
Análisis de la efectividad de las políticas públicas de Arreglo Productivo Local para el desarrollo local desde la teoría institucional

El objetivo de la investigación fue identificar las políticas públicas explican el fuerte desarrollo económico del Arreglo Productivo Local (APL) de muebles de Arapongas (PR), de 2000 a 2012, basado en la perspectiva institucional. Por lo tanto, un estudio de caso se hizo, y la fase cualitativa se basó en el análisis de contenido temático de documentos, realizado en 2012, que apoyó la fase cuantitativa mediante la aplicación de un cuestionario estructurado aplicado en 2013, junto con 38 empresas del APL. Las condiciones del entorno institucional cambiaron el entorno técnico con el fin de permitir el apoyo del patrón de desarrollo observado, pero estuvieron muy debajo de las expectativas para la mejora de la competitividad y los beneficios económicos que se esperan para las empresas de acuerdo con un modelo de APL, debido a las limitaciones en las relaciones sociales, para proporcionar la confianza entre los actores locales y reducen el aislamiento en pequeños grupos y la competencia individual.

Palabras clave: políticas públicas; desarrollo económico; contexto institucional; relaciones sociales.

An analysis of the effectiveness of public policies relating to Local Productive Arrangements (LPA'S) on local development from the perspective of institutional theory

The aim of this paper was to identify to what extent public policies were responsible for the strong economic development seen in the Arapongas/PR furniture-focused Local Productive Arrangement (LPA), between 2000 and 2012, as seen from an institutional perspective. The research for this paper based itself on a case study using both qualitative and quantitative methods. The qualitative phase involved the analysis of the thematic content of documents, carried out in 2012, which then supported the quantitative phase through the application of a structured questionnaire in 2013 to 38 companies within the LPA. The conditions of the institutional environment altered the technical environment in terms of allowing for the level of development observed to be sustained. However, they proved much weaker than expected in terms of improving the competitiveness of and economic benefits to these companies as per the APL model disseminated. This was evident in the limitations seen in social relations, which were too weak to offer local actors a degree of trust and to reduce isolation in small groups and individual competition.

Keywords: public policies; economic development; institutional context; social relations.

\section{Introdução}

Embora os estudos sobre políticas públicas sejam desenvolvidos em diferentes áreas do conhecimento (economia, ciência política, geografia, administração pública, entre outras), ainda há muita divergência acerca de seu significado, estimulando uma ampla gama de análises sobre as instituições, regras e modelos (Souza, 2006; Bevir, 2011). As conceituações, em um sentido mais amplo, que estão relacionadas com a concepção intrínseca de governança se referem às questões de coordenação social e de padronização de regras que orientam ações.

Diante disso, os governos enfocam dois importantes aspectos, que são a tomada de decisão e a utilização de recursos com vista à alteração das condições sociais (Peters, 2011). Nesse contexto, adotar-se-á neste artigo o conceito de políticas públicas como ações imbuídas 
de teor político que visam o desenvolvimento local e setorial, de modo a contribuir efetivamente para a sustentabilidade das empresas, o aumento de suas vantagens competitivas e o crescimento socioeconômico de uma região ou setor (Frey, 2000).

Nesse sentido, desenvolvimento local diz respeito à promoção de condições e/ou situações desejáveis para a sociedade, em âmbito socioterritorial, enquanto desenvolvimento setorial visa a melhoria da competitividade de um determinado setor (Martinelli e Joyal, 2004). Esse processo, em uma visão racionalista, é considerado pensado, planejado, promovido ou induzido; enquanto neste trabalho consideram-se o processo de recursividade entre as instituições e a capacidade de agência dos atores sociais envolvidos. Em adição, a noção de política pública empregada está restrita ao domínio econômico, o que não esgota, nem a ela se reduz, outras de finalidades distintas, como saúde ou educação. Ainda para o caso específico, optou-se pelo uso no plural, políticas públicas de APL, uma vez que envolvem ações diversas, realizadas por atores também distintos. Entre os principais se destacam: Ministério de Indústria e Comércio, Secretarias de Estado de Indústria e Comércio, Banco do Brasil, Sebrae e Federações de Indústria, que convergem para que os arranjos produtivos locais sejam incentivados como modelo de desenvolvimento econômico regional.

O objeto de análise foi o Arranjo Produtivo Local de Móveis de Arapongas, localizado no Norte do Paraná. Investigações que considerem a análise econômica stricto sensu, ou de modelos gerenciais imersos nas relações sociais, pressupõem esferas não autônomas dos fenômenos, em conformidade com Weber (1994) e os pressupostos do institucionalismo de base sociológica. Por sua vez, o fenômeno dos APLs, enquanto aglomeração de empresas que buscam se desenvolver pelo compartilhamento de recursos ao longo do tempo, envolve, além de aspectos geoeconômicos, uma dimensão simbólica que está implícita na interação social entre os atores imersos socialmente.

De acordo com Porter (1998), clusters se constituem em concentrações geográficas de empresas e instituições, ligadas por aspectos que podem ser compartilhados e complementados entre si. Essas empresas cooperam e colaboram para o desenvolvimento de vantagens econômicas e estratégicas. Segundo La Rovere e Shehata (2007), a diferença básica entre o conceito de cluster e de sistemas produtivos locais é que estes últimos, além de indicarem a presença de externalidades, como vantagens de aglomeração, colocam em destaque o papel das instituições, não apenas do governo, mas de instituições financeiras, de treinamento e pesquisa. Colocam assim em evidência o papel dos agentes locais para mobilizar um setor produtivo. Além disso, o sistema produtivo local está relacionado com um determinado setor ou atividade, enquanto cluster é definido como uma aglomeração de empresas, que podem ou não pertencer ao mesmo setor.

Assim, os APLs seriam sistemas produtivos em formação (La Rovere e Shehata, 2007), moldados por processos de aprendizado evolucionários, e caracterizados pela existência de sistemas cognitivos de compartilhamento de conhecimento entre empresas e entidades (Cassiolato, Lastres e Vargas, 2002; Lastres, Cassiolato e Maciel, 2003).

Em relação aos APLs paranaenses, no levantamento realizado pela Rede de Pesquisa em Sistemas e Arranjos Produtivos e Inovativos Locais (RedeSist, 2009:11-13), em 2003, 
as 114 aglomerações produtivas identificadas no Paraná foram responsáveis por 34,7\% dos empregos industriais formais e $17,3 \%$ do faturamento do setor industrial do estado naquele ano. Os APLs e suas variações tornaram-se relevantes em diversos locais no mundo tendo em vista o desenvolvimento econômico e social gerado nas regiões em que foram estabelecidos.

No caso em análise, sua importância no estado do Paraná possui representatividade, o que torna o caso e a proposta de APL interessantes para o estudo. Sobre a situação do mercado moveleiro, segundo o Sima (2013), os móveis produzidos em Arapongas destinam-se ao mercado consumidor nacional (92\%). O APL se destaca como o maior polo moveleiro do Paraná, com faturamento, em 2012, de R \$1,403 bilhão, dos quais U\$107,04 milhões foram de exportações. Em relação ao número de empregos, o APL gerou, em 2012, 11.333 empregos diretos só em Arapongas. A participação das indústrias moveleiras no PIB do município foi de $67,31 \%$ e no PIB nacional do setor de móveis foi de $9,88 \%$.

Neste trabalho, foi adotada a nomenclatura de APLs, visto que corresponde à adotada pelas entidades governamentais e de apoio (Rede APL Paraná) para caracterizar tais regiões. Dessa forma, o problema de pesquisa consistiu em investigar por meio da perspectiva institucional de análise de que modo as relações sociais afetaram as condições do ambiente técnico, no sentido de avaliar: qual a efetividade das políticas públicas de APL no desenvolvimento econômico do APL de Móveis de Arapongas, no período de 2005 a 2012?

A contribuição teórica primordialmente é vista na busca por suprir o gap que emerge do fato de a dimensão cultural-cognitiva não ter sido suficientemente trabalhada na literatura que tradicionalmente tem pesquisado os APLs com base em aspectos predominantemente econômicos (Rodrigues, 2003; Suzigan et al., 2004; Putnam, 2006; Rocha e Bursztyn, 2006; Silva et al., 2009; Vicari, 2009).

Segundo Dover e Lawrence (2010), a teoria institucional já possui boa difusão junto à comunidade acadêmica, mas ela ainda é desconhecida pelos gerentes das organizações. A despeito disso, este estudo tem contribuição prática no sentido de que busca a compreensão da efetividade de políticas públicas e a análise das relações sociais nesse processo.

Tomou-se, para fim de localizar a análise gerencial e, em parte econômica, a justificativa e localização do institucionalismo na compreensão dos fenômenos organizacionais, a posição de Machado-da-Silva e Fonseca (2010). Para os autores, o arranjo das condições materiais empregadas para produção de resultados propostos pelas organizações se refere ao ordenamento racional dos fatores, isto é, eficiência. Nessa condição, ela antecede a ação organizacional, uma posição ex ante, diante dos resultados e objetivos pretendidos, se avalia o nível de alcance obtido, tratado em termos de eficácia, uma posição ex post, o que resume muito da literatura gerencial tradicional. Contudo, a ação organizacional em si é um conceito vazio. Nesse ponto, a teoria institucional se dedica a compreender por que um determinado conjunto de crenças, valores, práticas e ações foram realizados. Trata-se aí de entender a legitimidade desses elementos como guia, em outras palavras, o que é efetivamente feito. Para tanto, na sequência são apresentados os fundamentos teóricos do trabalho. 


\section{Contexto institucional}

Na teoria institucional, os norteadores das práticas sociais são as instituições que configuram e conferem certas probabilidades maiores de ação em detrimento de outras. Não se trata de predeterminação, no sentido de que as coisas vão acontecer de modo uniforme, independente da vontade dos atores sociais, e sim que eles nascem numa realidade institucionalizada com tipificações que dizem como as coisas devem ser, exercendo assim pressão de configuração. Mas não se pressupõe a passividade dos sujeitos, muito menos que sujeitos em realidades distintas, sob a mesma pressão, irão manifestar a mesma intensidade de conformidade.

Meyer e Rowan (1977) observaram que valores institucionalizados na sociedade permeiam as estruturas e formas organizacionais, destacando que a análise de aspectos instrumentais deve ser mais complexa, incluindo a presença de elementos culturais e simbólicos no estudo organizacional. As organizações são direcionadas para incorporarem as práticas e os procedimentos definidos por conceitos racionalizados predominantes e institucionalizados na sociedade. Assim, as organizações são influenciadas pelos contextos institucional e relacional e tornam-se isomórficas para assegurar aprovação social (legitimidade), que provê benefícios de sobrevivência, mesmo sendo as práticas institucionalizadas contrárias à eficiência (Greenwood et al., 2008).

Sobre a relação do trinômio instituição-legitimidade-aceitação, duas considerações são oportunas. A primeira é autoevidente: instituições são guias da ação na medida em que são legítimas, e são legítimas na medida em que são aceitas, e isso se aplica aos atores envolvidos no escopo da instituição, mas não para todos e quaisquer atores. Contudo, esse entendimento razoavelmente comum é tautológico: o que aceito é legítimo, e o que é legítimo é aceito.

Recorrendo a Weber (1994), há uma questão anterior à aceitação que é relevante. Para os casos concretos, alguns dos participantes atribuem o mesmo significado, a motivação individual é diversa para os indivíduos, pode ser utilitária pela percepção de vantagens, por amizade em apoio ao outro que aceita, por fidelidade contratual, por sentimento de solidariedade, entre outros. Além disso, não precisam ser estáveis no tempo, o que aceita por apoio a um amigo pode posteriormente aceitar pela percepção dos benefícios, ou pode evoluir conjuntamente para um senso coletivo.

Desse modo, o contexto institucional se refere ao conjunto dos elementos ambientais de natureza institucional e técnica que envolve as organizações e com o qual elas interagem. Por exemplo, as empresas são motivadas a assegurar a legitimidade pela aparência do "moderno, eficiente e racional, mesmo por meio de procedimentos não funcionais" (Greenwood et al., 2008:8). Pode apresentar-se em três níveis: local/regional, nacional e internacional, formando, assim, o contexto institucional de referência adotado por uma organização (Scott, 1983; Guarido Filho e Machado-da-Silva, 2001; Greenwood et al., 2008; Machado-da-Silva e Fonseca, 2010), uma vez que os dirigentes, ao definirem suas ações, levam em conta o nível do contexto. Cabe acrescentar que não é uma livre escolha, o nível depende das crenças, valores que permeiam os atores com os quais interagem, ou pelo menos são afetados. 
A influência do contexto institucional sobre as organizações conduz a um fenômeno denominado de isomorfismo, que consiste na tendência de as organizações assemelharem-se a outras, dentro de uma população, quando submetidas a um mesmo conjunto de condições ambientais, comportando variações de intensidade. DiMaggio e Powell (1983) descrevem três tipos de pressões institucionais - mecanismos institucionais, segundo Scott (2008) - que levam a mudanças isomórficas, denominadas de coercitivas, normativas e miméticas.

O isomorfismo coercitivo resulta de pressões formais e informais exercidas sobre uma organização pelo Estado, por outras organizações, ou ainda por expectativas culturais da sociedade, das quais ela é dependente. Assim, a organização é obrigada a adotar estratégias similares às outras do mesmo setor, decorrentes de pressões e expectativas dessas entidades, que impõem mecanismos de regulação (regras, leis e sanções) sobre suas atividades. O isomorfismo normativo decorre do processo de profissionalização que tende a tornar as condições e os métodos de trabalho mais homogêneos, a partir de interpretações e modos de atuação comuns em face das exigências organizacionais. Esse processo leva as organizações a adotarem padrões de atividade semelhantes, para assegurar aos profissionais os mesmos benefícios oferecidos pelas organizações concorrentes.

Por fim, as organizações podem perceber que, quando submetidas a ambientes de incerteza e ambiguidade, a melhor forma de agir é imitar organizações tidas como modelo de sucesso, gerando o isomorfismo mimético. Carstens e Machado-da-Silva (2006) mencionam que as organizações que utilizam as mesmas práticas usadas por outras são vistas pelos reguladores e pela sociedade em geral como mais legítimas do que as organizações que adotam um comportamento fora do que consideram natural ou habitual.

\subsection{Ambientes institucional e técnico}

O ambiente institucional diz respeito a regras e procedimentos socialmente elaborados que vigoram num determinado contexto social, entendidos como guias para a ação que, sob a devida conformidade da organização, lhe proporcionam legitimidade e suporte contextual (Guarido Filho e Machado-da-Silva, 2001; Scott, 2002; Machado-da-Silva e Fonseca, 2010). Scott (2008) atribui pesos iguais aos elementos institucionais - regulativo, normativo e cognitivo - e ressalta a importância de identificar as condições que caracterizam determinado tempo e lugar e que influenciam a forma, o funcionamento e a legitimidade das organizações.

A tendência à homogeneização não exclui a competição, de modo que existe espaço para uma postura proativa das organizações sobre o seu ambiente, visando ao alcance de objetivos (Machado-da-Silva e Fonseca, 2010).

Entre as variantes para se definir e separar ambientes institucional e técnico, parece adequado para este trabalho o entendimento de Tsebelis (1998), segundo o qual os atores agem em duas arenas. A mais visível é a do jogo: uma vez estabelecidos critérios de competição, regulação, preços, mercados, qualidade, objetivos entre outras variáveis (para bem ou para mal), competem em si, e essa é a essência do ambiente técnico. Mas os atores não são 
passivos e atuam também na arena institucional, buscando alterar regras em seu favor. Por exemplo, o lobby de setores para criar barreiras tributárias que os proteja de concorrência internacional ou negociação de benefícios de redução de carga tributária, entre outras, que, uma vez alteradas, mudam o jogo em que atuam. Nesse plano, trata-se do ambiente institucional, com suas crenças, valores, normas e coerções, que se tornam guias da ação. É indispensável mencionar, principalmente para o caso estudado, que as ações (ambiente técnico), de forma continuada e recursiva, é que de fato conferem às instituições sua concretude, em oposição a permanecer apenas como potência de possibilidades.

Como complemento, visando maior clareza do estudo feito, as políticas públicas de APL foram consideradas parte do ambiente institucional. Nesse sentido, apenas um modelo de gestão cooperada e compartilhada, que envolve ações estratégicas coletivas, que são incentivadas por atores do campo, mas não executadas por eles. De outro lado, existe o que efetivamente ocorre no nível local, no locus de interação dos atores, isto é, a efetividade alcançada por essas políticas.

Admite-se, portanto, que os sujeitos e suas ações não são passivos diante de pressões para mudança (sem julgar o mérito de que suas escolhas sejam melhores para esses próprios sujeitos). Essa questão tem recebido cada vez mais atenção nos estudos institucionais que privilegiam o entendimento das organizações, relações interorganizacionais e ambientes mais complexos, e inclui os atores que são reconhecidos e possuem alguma capacidade de influência mútua. É certo que esse entendimento já está contido no conceito de campo organizacional; contudo, notadamente nos anos de 1970 e 1980, as análises de mudança e persistência concentram-se em mecanismos isomórficos, conferindo um caráter estrutural-funcional o qual esta abordagem procura atenuar. A microanálise, que vem se esboçando, trata da interação no local da ação, de comunidades (Marquis, Glynn e Davis, 2007; Marquis, Lounsburry e Greenwood, 2011) e até mesmo da constituição do sujeito por meio da ação, permeado por lógicas institucionais mais marcantes para os casos concretos. É nesse escopo que este trabalho se posiciona, nem sendo relevante a natureza ou conceituação de políticas públicas, mas tomá-las como fenômeno que, por meio de atores indutores do campo, geram pressão institucional para a conformidade e, aí sim como questão central, os atores locais reagem a elas.

Tal pressuposto é válido em APLs, e essa concepção possibilita uma análise que pode abranger tanto aspectos relativos à ação quanto à interpretação, ou seja, admite que as organizações criam uma representação de seu ambiente e que possuem a capacidade de modificá-lo, ressaltando a interdependência do ambiente e da organização (Scott, 1983).

O ambiente técnico, por sua vez, caracteriza-se pelo espaço de competição na ótica econômica, cuja dinâmica de funcionamento desencadeia-se por meio da troca de bens e serviços, de modo que as organizações que nele se incluem são avaliadas pelo processamento tecnicamente eficiente do trabalho (Machado-da-Silva e Fonseca, 2010). Constitui-se dos fatores que suprem as dependências econômico-funcionais das organizações que vão determinar sua posição no mercado e seu potencial de concorrência (DiMaggio e Powell, 1983; Guarido Filho e Machado-da-Silva, 2001).

É oportuno destacar que pela expressão "espaço de competição na ótica econômica" não se podem entender apenas organizações estritamente voltadas para a produção de ri- 
queza, mas quaisquer organizações na medida em que estão sujeitas a captação de recursos e pessoas para consecução de seus objetivos, e não estão livres das limitações da escassez, que é provavelmente a nota mais definidora da economia como ciência.

Machado-da-Silva e Lima (2002) constataram que a competitividade não depende apenas de fatores econômicos, mas também de uma conduta socialmente valorizada que garanta a legitimidade e a sobrevivência no contexto ambiental, resultando num "isomorfismo competitivo" (Machado-da-Silva e Fonseca, 2010:40). Esse pressuposto deve ser levado em conta ao se investigarem os fatores determinantes do ambiente técnico, conforme observado no caso investigado. Cada uma dessas facetas explica parte da competitividade empresarial, pois revela não apenas a luta das organizações por diversos recursos, mas também os diferentes significados atribuídos ao próprio constructo (Scott, 2008).

Para Machado-da-Silva e Fernandes (1998:49), "indústrias tendem a se modelar mais pelos ambientes técnicos, uma vez que o controle ambiental é exercido sobre os resultados em termos de quantidade e qualidade de bens". O presente trabalho, ao investigar o setor industrial moveleiro de Arapongas, corrobora essa tendência quando identifica de que modo as políticas públicas influenciaram o desempenho das empresas do APL para explicar o acentuado desenvolvimento econômico constatado.

Nesse âmbito, conforme comenta Gonçalves (2007:8), "quando se fala em eficiência, e em arranjos estruturais que maximizam a eficiência, pode-se tratar tanto da estrutura organizacional quanto da estrutura da indústria e do mercado no qual se insere a organização". Segundo Scott (1983), ao se abordar um segmento da indústria, pode-se alcançar razoável consenso sobre o conceito de ambiente técnico, em função das noções de dependência e de incerteza. Essas duas condições, além de caracterizarem o desenho das relações desse ambiente, também estabelecem formas estruturais e de comportamento para as organizações que nele se inserem. Assim, os aspectos econômicos do ambiente técnico utilizados para descrever o APL foram: benefícios econômicos, competitividade do setor, políticas públicas e situação do mercado; que foram identificadas empiricamente, por meio da análise de conteúdo temática, no nível do campo organizacional, conforme descrito na seção da metodologia. Tais constructos são explicitados na sequência.

\subsubsection{Benefícios econômicos e competitividade do setor}

O fundamento dos benefícios econômicos se refere às vantagens resultantes da aglomeração de empresas (Erber, 2008; Marshall, 1925) e podem ser entendidos como externalidades positivas que, de acordo com Nath (1969), existem quando a produção de uma empresa depende de alguma atividade de outra que faz parte da rede. Paci e Usai (2000) lembram que essas externalidades podem ser divididas em produtivas e tecnológicas. As de produção existem quando as empresas obtêm vantagens pecuniárias (como na criação de uma central de compras ou no aproveitamento de mão de obra e capacitação em conjunto) e/ou vantagens de localização (como no compartilhamento de infraestrutura). As tecnológicas existem quando há trocas de 
tecnologias e podem ser divididas em economias de especialização, quando a especialização de uma região favorece a inovação, e economias de diversidade, quando a diversidade de atividades de uma região cria um ambiente propício à inovação.

Rodrigues (2003) constatou que os APLs possibilitam às micro e pequenas empresas incrementos em seus processos produtivos, tanto em termos de volume de produção quanto em termos de aumento de possibilidades tecnológicas, por meio do compartilhamento de meios produtivos e de investimentos na busca por melhores tecnologias, sejam elas de produto, de processo ou de gestão. Outra vantagem associada é a promoção dos produtos locais, uma vez que a falta de uma marca forte ou de um nome representativo que defina os produtos produzidos pelas empresas isoladas pode levar a dificuldades de inserção no mercado e à restrição ao acesso a canais de distribuição fortes.

Com relação à competitividade do setor, é necessário apurar o quanto ela é valorizada no APL de modo a influenciar comportamentos organizacionais e a adoção de certas ações, cuja efetividade, influenciada pela noção de eficiência que prevalece no ambiente, gera resultados significativos para o setor como um todo.

Do ponto de vista técnico, a competitividade organizacional está ligada a obtenção, manutenção e uso de recursos apropriados para alcançar os índices econômicos e técnico-operacionais, valorizados e interpretados como expressões de competência e competitividade. A competitividade, nessa faceta da dimensão contextual, seria avaliada por meio de indicadores quantitativos de qualidade, produtividade, eficiência e desempenho econômico (Machado-daSilva e Lima, 2002:9).

O resultado aqui é medido em termos técnicos, mas o significado é substantivo, pois está no contexto institucional, a competição como valor para melhoria do desempenho, em oposição, por exemplo, a acordos de preço e não competição para preservar ganhos e reduzir riscos de falência.

Há situações distintas em que os atores imersos competem e situações em que eles cooperam. Diante das condições institucionais, econômicas e relacionais, pode haver colaboração competitiva ou membros distintos que se isolam e só competem. É preciso verificar se prevalece no APL a noção de que, ao participar de um arranjo, a cooperação ocorre para competir com um terceiro, externo aos membros que fazem parte do APL e os demais locais.

\subsubsection{Políticas públicas e situação do mercado}

Sobre as políticas públicas, Souza (2006:26) resume o tema como o campo do conhecimento que busca "colocar o governo em ação" nas diversas esferas, para produzir resultados ou mudanças no mundo real. "Após desenhadas e formuladas, desdobram-se em planos, programas, projetos, bases de dados ou sistema de informação e pesquisas. Quando postas em ação, são implementadas, ficando [...] submetidas a sistemas de acompanhamento e avaliação." As políticas públicas para APLs focam o desenvolvimento local e setorial de modo a contribuir efe- 
tivamente para a sustentabilidade das empresas, o aumento de suas vantagens competitivas e o crescimento socioeconômico de uma região ou setor (Frey, 2000).

Reiterando a distinção fundamental na literatura recente que destaca o locus da interação, mais comumente referido como comunidade, privilegia-se aqui o conceito em Putnan (2006), na qual a característica distintiva é o sentimento de pertença que produz propriamente uma coletividade, em oposição a pessoas que coexistem em sociedade com as demais mantendo a individualidade nas relações sociais "mecânicas" com o conjunto maior. Nesse conceito e nas pesquisas que possuem essa perspectiva, a capacidade reativa, adaptativa e negocial se manifesta ante as pressões institucionais. Isto produz uma tensão, com variações de intensidade. Tanto contribui para explicar por que os diversos estudos sobre isomorfismo concluem por assemelhamento de organizações, mas não identidade ou simetria plena, quanto produz diferenças entre o modelo de APL disseminado, que é o conteúdo da pressão institucional, e sua efetividade no caso em análise.

Nesse sentido, Sausen e colaboradores (2014) consideram que a abordagem do desenvolvimento local deve contemplar o objetivo do desenvolvimento sustentável e perdurável, razão por que deve integrar as dimensões econômica, social e ambiental. Iniciativas que devem, assim, segundo os autores, conciliar a eficiência na alocação dos recursos, a equidade na distribuição da riqueza e do emprego e o equilíbrio em termos de preservação e cuidado com o meio ambiente.

Em relação à situação do mercado, reconhece-se que ele funciona como um processo competitivo de descoberta que é posto em movimento pela miríade de planos e atividades de produtores e consumidores que colaboram e concorrem sob a divisão social do trabalho (Hayek, 1978). De acordo com Outhwaite e Bottomore (1996:460):

O processo de mercado é o resultado de todas as atividades de seus participantes, mas não é produto nem do desígnio nem da deliberação de ninguém [...]. A ordem do mercado é uma consequência involuntária da busca pelos indivíduos de seus próprios interesses [...], a economia de mercado nem começa em equilíbrio geral, nem poderá jamais alcançá-lo. Em vez disso, provê [...] uma ordem sempre em evolução, um padrão discernível de acontecimentos [...], um sistema de mercado desimpedido dissemina o conhecimento a respeito da relativa escassez de bens e serviços entre os participantes do mercado, que usam cálculos econômicos [...] para interpretar a informação embutida em preços competitivos.

A situação do mercado, em termos de conjuntura econômica e tendências, pode ser apreciada por meio de sua amplitude, padronização de produtos e serviços, taxa de crescimento e quantidade de contratos de trabalho de modo a se obter uma explicação para o crescimento econômico registrado. Uma parte do argumento para marcar o período inicial da situação do mercado é o uso da política pública, como instrumento de fomento ao desenvolvimento para criar e alavancar o APL. Portanto, o teste da hipótese 1 ajuda a justificar o crescimento econômico ao longo do tempo no APL de Móveis de Arapongas. 
Hipótese 1: As condições favoráveis do ambiente técnico de uma indústria resultantes de políticas públicas e situação do mercado geram maior competitividade do setor e benefícios econômicos num APL.

Além disso, pressupõe-se que a competitividade do setor e os benefícios econômicos podem ser alavancados pelo desenvolvimento das relações sociais entre os atores imersos no APL. Por isso, faz-se necessário corroborar se:

Hipótese 2: O desenvolvimento das relações sociais gera maior competitividade no setor e benefícios econômicos em APLs.

Para tanto, é necessário dimensionar o contexto relacional para fundamentar a hipótese 2 e a hipótese 3 apresentada em seguida, possibilitando a construção do esquema de análise do artigo.

\subsection{Contexto relacional}

Percebe-se que, em APLs, o foco de análise deixa de ser a empresa individual passando a preocupação a ser mais concentrada nas relações entre as empresas e entre elas e as demais instituições, dentro de um espaço geograficamente definido, assim como busca-se privilegiar as características do ambiente onde as mesmas se encontram (Rocha e Bursztyn, 2006). Dessa forma, para fortalecer as relações, o APL é instituído por meio de uma governança local formada por representantes das entidades participantes e pelas empresas que fazem parte do arranjo. A governança de APLs, segundo o Ipardes (2006b), diz respeito aos diferentes modos de coordenação, intervenção e participação nos processos de decisão locais dos diferentes agentes (Estado, empresas, cidadãos e trabalhadores, organizações não governamentais) e às diversas atividades que envolvem a organização dos fluxos de produção, bem como o processo de geração, disseminação e uso de conhecimentos.

Segundo o Sebrae (2003), é fundamental a instância da governança e o estabelecimento de um modelo de gestão para a condução das atividades no âmbito do APL. Essa instância tem função executiva de coordenar e alinhar as iniciativas, observando prazos, atividades, atribuições e responsabilidades, motivação, comprometimento, entre outros. O grupo gestor da governança pode ser formado por empresários e representantes de entidades presentes no APL, que tem como objetivo promover integração entre empresas e entidades mediante a execução de várias ações de interesse coletivo.

Assim, o contexto relacional se refere ao histórico das relações entre atores sociais definido como o conjunto de fatores perenes ao longo do tempo para preservar e fortalecer o comportamento reciprocamente referido, quanto ao seu conteúdo de sentido, entre atores sociais imersos num determinado campo organizacional e que têm a probabilidade de repetição contínua (Granovetter, 1992; Weber, 1994).

Neste trabalho, o contexto relacional foi descrito por meio do desenvolvimento das relações sociais que dizem respeito à evolução e intensificação dos laços entre os atores imersos no campo e é fator decisivo para que um conjunto de padrões, como os que fundamentam 
o modelo prescrito de APL, seja adotado, implementado, internalizado e difundido entre os atores imersos. Uma relação social pode ter um caráter transitório, de permanência, e o sentido dela pode mudar com o tempo. Geralmente, o conteúdo do sentido que permanece é expresso por meio de máximas, cuja observação os participantes esperam dos parceiros e pelas quais orientam suas próprias ações. "Isto ocorre tanto mais quanto mais a ação [...] se oriente de maneira racional — seja referente a fins ou a valores" (Weber, 1994:17). Desse modo, a pesquisa também investigou se:

Hipótese 3: O desenvolvimento das relações sociais nos APLs afeta positivamente a efetividade de políticas públicas e o desenvolvimento econômico do mercado (situação do mercado).

Figura 1

Esquema de análise proposto

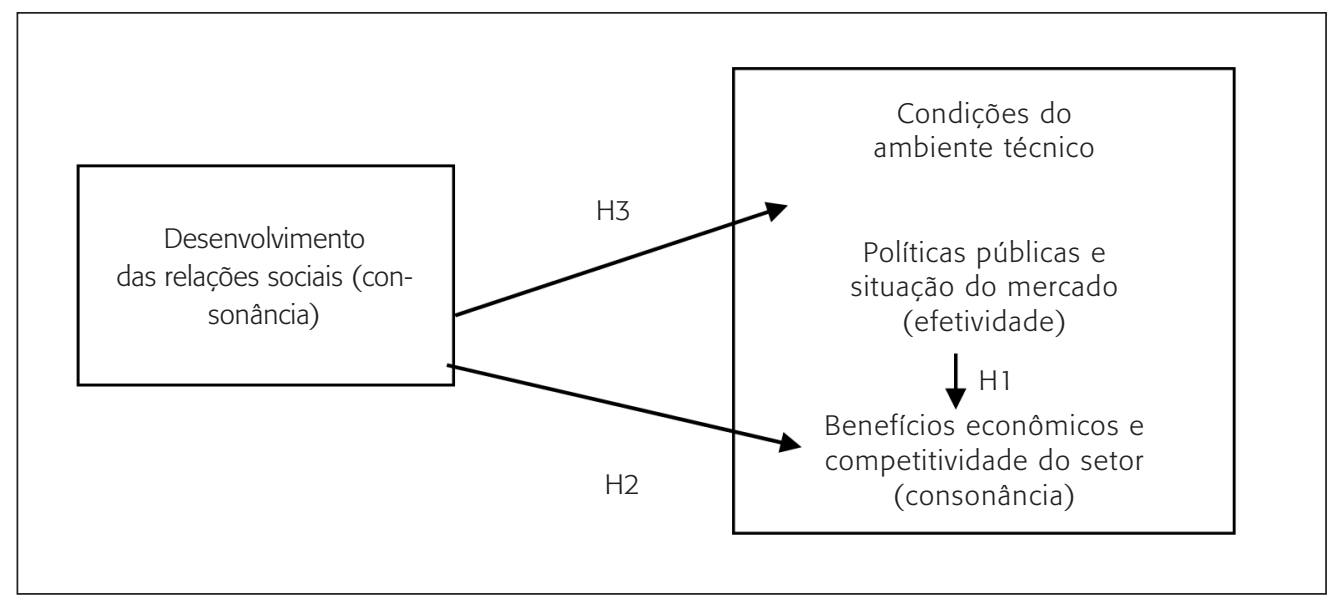

Fonte: Elaborada pelos autores.

A figura 1 apresenta o esquema de análise para avaliar se as relações sociais presentes no caso cumpriram os requisitos relacionais necessários à implementação efetiva do modelo de APL. A próxima seção apresenta a metodologia utilizada para a construção do referido esquema de análise e para realizar o teste das hipóteses apresentadas.

\section{Metodologia}

\subsection{A situação em estudo}

Segundo a pesquisa do Ipardes (2006a), até meados dos anos 1970, a economia de Arapongas era baseada na agropecuária, particularmente na extração de madeira, criação de gado e plantações de café. Após a grande geada de 1975, que destruiu a maior parte dos cafezais, os 
municípios da região sofreram uma reestruturação da atividade econômica local, passando a focar seus esforços na atividade moveleira.

Em 1978, foi criada a Associação Profissional das Indústrias da Serraria, Carpintaria, Madeiras Compensadas e Laminadas e da Marcenaria de Arapongas, ou Associação dos Moveleiros de Arapongas. Em 1982, essa associação se transformou no Sindicato das Indústrias de Móveis de Arapongas (Sima). Na década de 1990, apesar da geração de emprego industrial local, as ações do setor eram dispersas e sem foco. Em 1998, a partir do Planejamento Estratégico do Polo Moveleiro da Região Norte do Paraná, traçaram-se as diretrizes para transformar a indústria de móveis de Arapongas num polo moveleiro nacional. Com isso, foram implementados programas e projetos tais como: o Programa de Autossustentabilidade de Matéria-Prima para o Polo Moveleiro (Simflor) com objetivo de autossustentabilidade florestal; a transferência, em 2003, do Senai/Cetman (Centro Nacional de Tecnologia da Madeira e do Mobiliário), da Região Metropolitana de Curitiba para Arapongas, tendo como objetivo qualificar a mão de obra; e o Centro de Tecnologia em Ação e Desenvolvimento Sustentável (Cetec), que tinha o objetivo de apoiar e executar programas, projetos e serviços na área ambiental. Dessa forma, foram se configurando as instituições vigentes no ambiente institucional.

Em 2004, após diversas reuniões promovidas pelo Sima e pela Federação das Indústrias do Estado do Paraná (Fiep), foi criado o Arranjo Produtivo Local de Arapongas. Segundo dados do Sima (2013), o APL é composto pelos municípios de Apucarana, Arapongas, Cambé, Rolândia e Sabáudia, num total de 284 empresas, das quais Arapongas participa com 163, ou seja, 57,3\% do total de empresas de fabricação de móveis da região.

\subsection{Considerações metodológicas}

Neste trabalho, a interpretação é o mecanismo cognitivo que promove a reciprocidade entre ação e instituição e, por conseguinte, sua simultaneidade no contexto ambiental (Fonseca e Machado-da-Silva, 2010). Tal conexão entre instituição, ação, interpretação e pressões ambientais constitui o fundamento da teoria institucional. Segundo Vasconcelos (2004:162),

a origem da teoria interpretativa moderna e da visão construtivista que dela decorre pode ser remetida à obra de Weber (1994) e sua proposta de sociologia interpretativa. Max Weber [...] adota uma posição intermediária entre o objetivismo e o subjetivismo, quando propõe a adoção de um modo capaz de combinar estes dois polos. [...] se posiciona distintamente contra a validade absoluta das leis gerais em ciências sociais sem, no entanto, negar que os métodos quantitativos têm importante papel na generalização do conhecimento.

Uma vez delimitado o arcabouço teórico e após uma aproximação com o campo, foi possível elaborar a seguinte pergunta de pesquisa: qual a efetividade das políticas públicas de APL para incrementar o desenvolvimento econômico do APL de Móveis de Arapongas, no período de 2005 a 2012? Para responder a essa pergunta e testar as três hipóteses, foi adotada a 
estratégia de estudo de caso simples seccional (Yin, 2005), que levou em consideração dados históricos e os contextos institucional e relacional do setor. Para Chaffee e Tierney (1988:14), "estudos de caso envolvem essencialmente pesquisa qualitativa, ainda que empreguem técnicas quantitativas como forma de confirmar, modificar e estender as observações". Ainda, segundo Stake (2000), o estudo de caso não é uma escolha metodológica, mas uma escolha do que será estudado.

Ao levar em conta o pressuposto da predominância das condições do ambiente técnico em indústrias, a análise privilegiou o isomorfismo competitivo. Assim, foram realizados os seguintes procedimentos para operacionalizar as dimensões desse ambiente, bem como do contexto relacional.

O ambiente técnico foi operacionalizado mediante análise de conteúdo temática para a identificação: dos (1) benefícios econômicos advindos da aglomeração de empresas (externalidades positivas); das (2) políticas públicas disseminadas pelos agentes públicos (ações de governo); dos indicadores quantitativos de qualidade, produtividade, eficiência e desempenho econômico que caracterizam a (3) competitividade do setor; e da (4) situação do mercado no respectivo setor em termos de amplitude, taxa de crescimento, padronização de produtos e serviços e quantidade de contratos de trabalho, de forma a identificar os atributos econômicos e técnicos exigidos das organizações pertencentes ao APL e sob os quais sua eficiência é avaliada. O contexto relacional, por sua vez, foi operacionalizado mediante análise de conteúdo temática para a identificação do nível de desenvolvimento das relações sociais entre os atores imersos no APL.

Para tanto, foram utilizadas as seguintes fontes: documentos internos do APL, contendo dados sobre os indicadores de desenvolvimento em relação à região de localização, entrevistas semiestruturadas com os membros da governança do APL e notas de campo. Os resultados obtidos na fase qualitativa da pesquisa foram desdobrados em indicadores que foram avaliados pelas empresas de cada APL por meio de questionário estruturado.

Para maior garantia de confiabilidade dos dados, além de a fase qualitativa ter sido conduzida pessoalmente por dois dos autores deste trabalho, decidiu-se que a aplicação dos questionários estruturados não seria por meio eletrônico, por não permitir controlar quem foram, de fato, os respondentes, nem por técnica de snow ball, pelo risco de envio dos questionários ser alterado por relações de amizade ou proximidade entre os sujeitos. Dessa forma, foram aplicados pessoalmente pelos pesquisadores.

A população de APLs, foco de políticas públicas no estado do Paraná, na ocasião da pesquisa, era de 22 aglomerados e a classificação desses APLs foi definida a partir de estudo realizado pelo Ipardes (2006b) e coordenado pela Secretaria de Estado do Planejamento e Coordenação Geral, objetivando identificar e caracterizar as aglomerações geográficas e setoriais de empresas que poderiam constituir APLs. Em um segundo momento, construiu-se uma tipologia adequada às especificidades do estado, levando-se em conta a respectiva importância das aglomerações para o setor em que estão inseridas e para a economia da região em que se localizam, resultando na classificação apresentada no quadro 1. 
O APL de Arapongas foi escolhido intencionalmente pela viabilidade de acesso para a pesquisa e por ser um Núcleo de Desenvolvimento Setorial e Regional (NDSR), sendo um APL de destaque pelo volume de seu faturamento e crescimento, além de ser o segundo maior polo moveleiro do Brasil.

Na fase qualitativa foram realizadas, no período de maio a agosto de 2012, seis entrevistas com os principais atores do APL, que foram gravadas e transcritas, sendo utilizado um roteiro de entrevistas semiestruturado. A partir dos documentos de fontes secundárias, das entrevistas e das notas de campo foi realizada a análise de conteúdo temática, conforme Bardin (2009), com o uso do software Atlas.ti (2012) que permitiu a identificação das dimensões mais relevantes dos ambientes técnico e relacional e seus respectivos indicadores; e elaborado um questionário estruturado para ser aplicado nas empresas.

Quadro 1

Tipologia dos APLs

\begin{tabular}{|ll|}
\hline Classificação & Características do APL \\
\hline $\begin{array}{l}\text { Núcleo de Desenvolvimento } \\
\text { Setorial e Regional (NDSR) }\end{array}$ & $\begin{array}{l}\text { Aglomerações que se destacam pela importância para uma dada região e pela sua } \\
\text { importância para o setor de atividade econômica no estado }\end{array}$ \\
$\begin{array}{l}\text { Vetor de Desenvolvimento Local } \\
\text { (VDL) }\end{array}$ & $\begin{array}{l}\text { Aglomerações com importância para o desenvolvimento local/regional, porém de menor } \\
\text { relevância para o setor no estado }\end{array}$ \\
Vetor Avançado (VA) & $\begin{array}{l}\text { Aglomerações com elevada importância setorial, mas com pouca importância para a } \\
\text { região, porque se encontram num tecido econômico maior e mais diversificado }\end{array}$ \\
Embrião (E) & $\begin{array}{l}\text { Aglomerações com potencial para o desenvolvimento, porém ainda pouco importantes } \\
\text { para o setor e a região }\end{array}$ \\
\hline
\end{tabular}

Fonte: Elaborado a partir de Ipardes (2006b).

Assim, a segunda fase da coleta de dados foi realizada de março a maio de 2013, quando foram aplicados um total de 38 questionários, representando $23 \%$ do total de empresas locais. Os dados foram tratados quantitativamente, de modo a complementar a análise qualitativa inicial.

O questionário estruturado foi elaborado a partir de indicadores das dimensões dos constructos identificadas na análise de conteúdo temática realizada na fase qualitativa da pesquisa e considerados adequados, uma vez que a consistência interna das dimensões foi considerada alta, conforme mostra a tabela 1 que apresenta os Alpha de Cronbach ${ }^{1}$ com valores acima de 0,7 , não havendo necessidade de remover itens das dimensões discriminados no questionário.

\footnotetext{
${ }^{1}$ É o coeficiente de confiabilidade que avalia a consistência de uma escala. O consenso geral sobre o limite inferior para o coeficiente é 0,7, embora possa diminuir para 0,6 em pesquisas exploratórias (Hair et al., 2010).
} 
Tabela 1

\section{Confiabilidade das dimensões dos constructos}

\begin{tabular}{|clc|}
\hline Constructo & \multicolumn{1}{c|}{ Dimensões } & Alpha de Cronbach \\
\hline \multirow{3}{*}{ Ambiente Técnico } & Benefícios Econômicos & 0,838 \\
& Competitividade do Setor & 0,958 \\
& Políticas Públicas & 0,744 \\
& Situação do Mercado & 0,845 \\
Contexto Relacional & Desenvolvimento das Relações & 0,909 \\
\hline
\end{tabular}

Fonte: Elaborada pelos autores a partir dos dados da pesquisa processados no SPSS (2011).

Durante a aplicação do questionário, foram contatadas 110 empresas de Arapongas; a maioria dessas empresas (em torno de 70\%) não soube dizer o que é APL e isso dificultou o retorno dos questionários, pois esses respondentes alegaram não estarem habilitados para responder por desconhecimento. Por si só, esse alto percentual de empresas sem interesse no APL, mesmo que possam ter auferido algum benefício indireto, é um bom indicador da efetividade limitada das políticas públicas em análise.

Em seguida, foram determinados os coeficientes de correlação entre as dimensões dos constructos envolvidas para avaliar as relações, conforme sugerido pela teoria e contempladas no esquema de análise. Para se realizar esses testes, as escalas de todas as variáveis foram consideradas intervalares para viabilizar estatísticas paramétricas, conforme recomendam Agresti e Finlay (2012).

Foi realizada uma análise de correlação entre as categorias analíticas do esquema proposto para identificar até que ponto há relação de influência entre elas no APL investigado e onde é mais provável que relações de causalidade se estabeleçam. Para tanto, foi utilizado o coeficiente de Pearson nas análises. Assim, as hipóteses construídas ao longo da base teórica foram testadas mediante teste $t$ de correlação para amostras independentes.

\section{Resultados e discussões}

$\mathrm{Na}$ análise dos dados, buscou-se o teste de hipóteses para verificar que, apesar de ter havido um significativo desenvolvimento econômico no APL de Móveis de Arapongas, isso não significou aumento de competitividade e nem de benefícios econômicos entre as empresas. Ao se testar a hipótese 1, a mesma foi rejeitada, pois não houve significância estatística para indicar influência da situação do mercado e das políticas públicas sobre a competitividade do setor e benefícios econômicos $(p>0,05)$. O coeficiente de Pearson foi de $-0,21$, indicando baixa correlação.

Essa rejeição mostra que as políticas públicas e a situação do mercado não têm afetado a competitividade do setor de móveis e nem gerado benefícios econômicos coletivos, 
apesar de o desempenho econômico das empresas do APL ter apresentado crescimento no faturamento, no período de 2000 a 2012, conforme mostra o gráfico 1. Nota-se que, no período entre 2000 e 2004, anterior à implementação e formalização do APL, o faturamento cresceu 86,05\%; já entre 2005 e 2012, com o APL em funcionamento, o crescimento foi de $64,67 \%$.

Gráfico 1

Evolução do faturamento do APL de Móveis de Arapongas

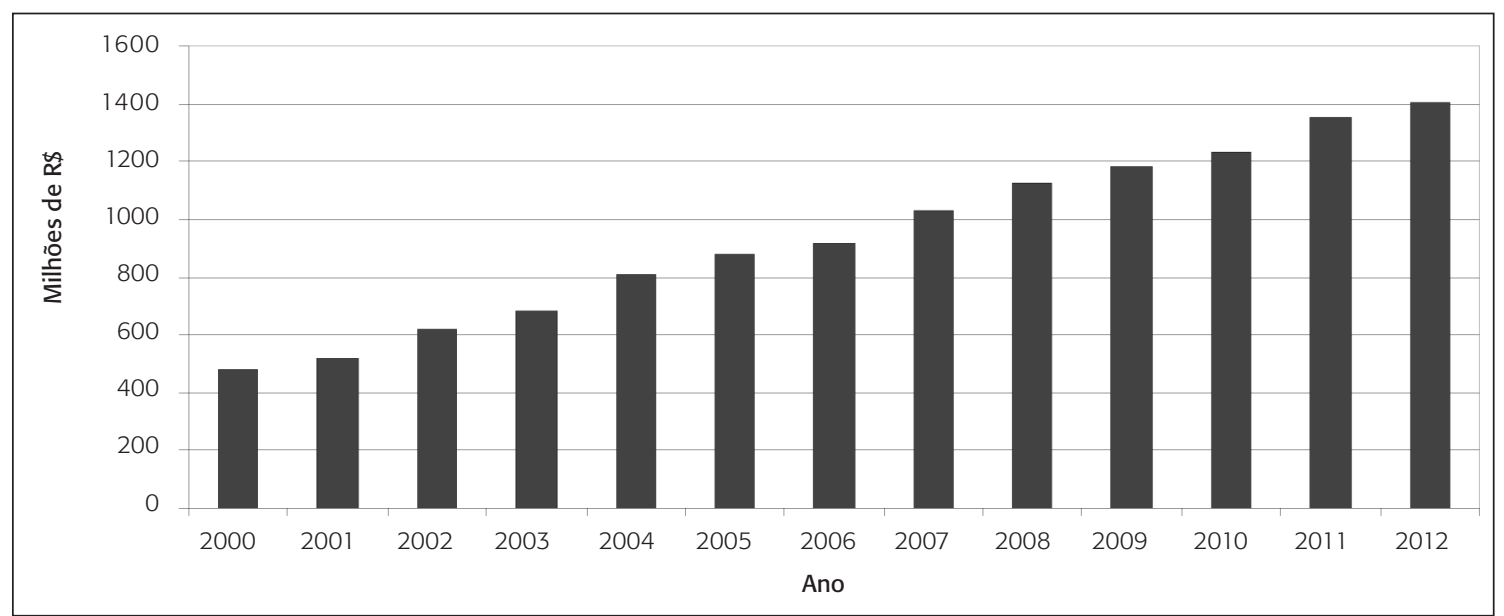

Fonte: Elaborado a partir dos dados do Sima (2013).

Essa constatação mostra que as empresas de Móveis de Arapongas atuam de forma mais isolada no setor, mantendo relações predominantemente comerciais suficientes para garantir o faturamento sem haver uma preocupação com a competitividade derivada da ação coletiva, um dos efeitos esperados do APL. Conforme Machado-da-Silva e Lima (2002) já haviam identificado, a competitividade não depende apenas de fatores econômicos, mas também de uma conduta socialmente valorizada que garanta a legitimidade, o que equivale a dizer efetividade, ou seja, ações condicionadas que conferem concretude às instituições na medida em que dependem de serem reafirmadas recursivamente.

Essa característica observada no APL investigado, que atua mais no mercado interno, corrobora a observação de Greenwood e colaboradores (2008) de que as organizações se tornam mais isomórficas para assegurar legitimidade que provê benefícios de sobrevivência, mesmo sendo as práticas institucionalizadas contrárias à eficiência (Greenwood et al., 2008), contudo com caráter mais simbólico e cerimonial do que como prática.

Em termos de taxa de crescimento do faturamento do APL, o gráfico 2 faz uma comparação com a taxa de crescimento da indústria nacional. Percebe-se que o crescimento do setor moveleiro de Arapongas acompanhou o crescimento da indústria nacional, com exceção dos anos de 2003 em que o APL teve um crescimento menor em 2009, quando houve um encolhimento da indústria nacional, mas com crescimento estável e positivo no período. 
Gráfico 2

Comparação entre a taxa de crescimento do faturamento do APL de Móveis e a da indústria nacional de 2001 a 2011

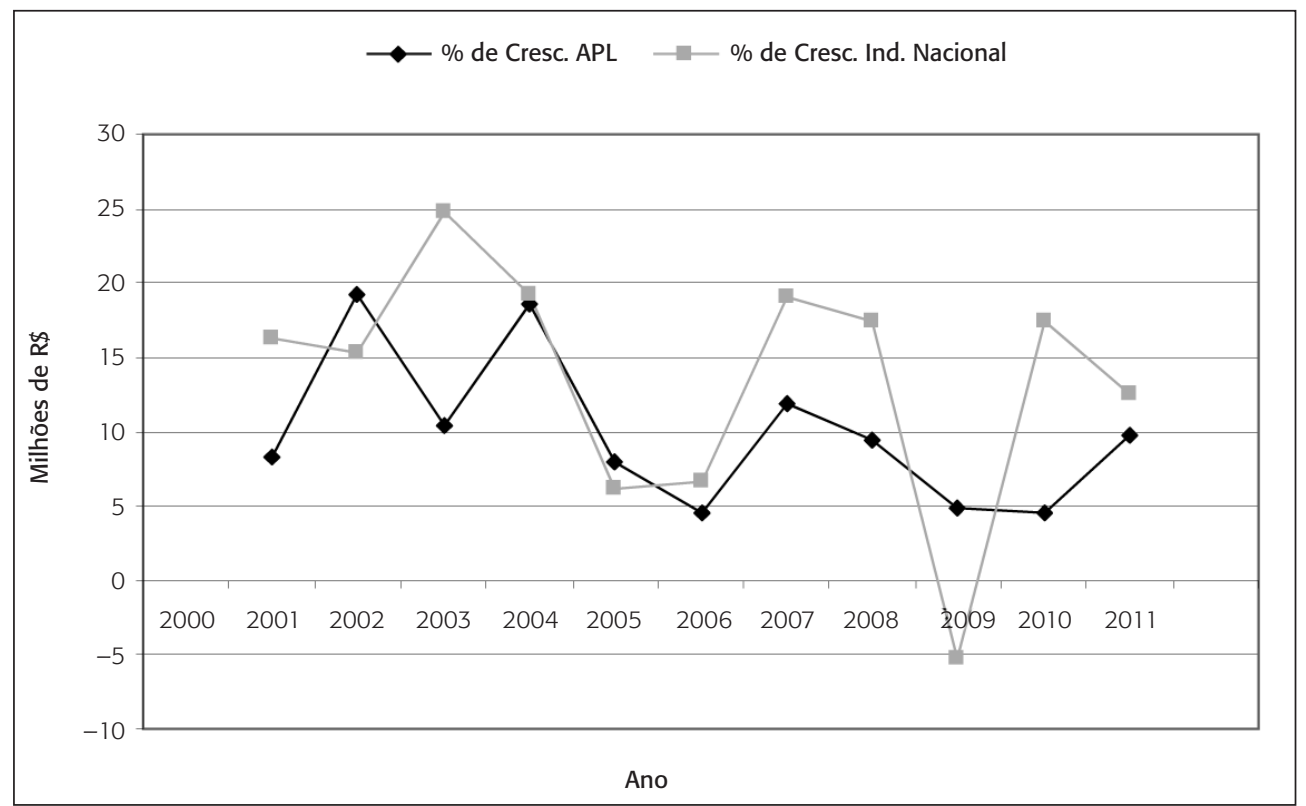

Fonte: Elaborado a partir dos dados do Sima (2013) e IBGE (2009).

Ao se analisar a correlação entre o desenvolvimento das relações sociais e a competitividade do setor, o coeficiente de Pearson foi de 0,96, caracterizando elevada correlação entre as variáveis e alta significância estatística com valor $p<0,05$; logo, a hipótese 2 foi aceita. O que se percebe no APL pelas observações realizadas é que os atores sociais buscam desenvolver relações sociais, mas encontram dificuldades para isso. No entanto, a criação do APL é política pública que depende de ampliar e diversificar as relações sociais, tendo em vista uma pressão institucional nessa direção.

Desse modo, verifica-se que as políticas públicas, como pressão normativa estabelecida, visam a acelerar o desenvolvimento local e melhorar a competitividade, conforme preveem Frey (2000) e Martinelli e Joyal (2004), mas isso ainda não se efetivou no APL de Móveis de Arapongas. O que reforça a distinção feita neste trabalho, pois as políticas públicas de APL como instituição, como regras do jogo, propostas e induzidas por outros atores no nível do campo, caracterizam o APL no ambiente técnico; e neste ambiente, o APL apresentou baixa efetividade no plano da ação, entre os atores imediatamente envolvidos no nível local em Arapongas.

Para avaliar se houve alguma relação entre o desenvolvimento das relações sociais sobre a situação do mercado, foi avaliada a correlação de Pearson, que foi de $-0,23$, portanto, baixa. O resultado indica que não houve significância estatística para haver correlação entre 
as variáveis; logo, a hipótese 3 foi rejeitada. Isso pode ser explicado pelo fato de que houve uma dissonância entre os atores sociais imersos no APL de Arapongas com respeito ao desenvolvimento das relações sociais, enquanto os indicadores da situação do mercado obtiveram um nível médio de importância.

Os resultados obtidos com os testes das três hipóteses podem ser explicados pela análise qualitativa das dimensões envolvidas. Em relação às dimensões do ambiente técnico, os atores sociais que participam da governança indicaram que, com relação a benefícios econômicos, há uma ausência de linhas específicas de crédito para o setor moveleiro e dificuldades para que as MPEs tenham acesso ao crédito para aquisição de máquinas, equipamentos e tecnologias de ponta, por exemplo; e desconhecimento dos programas de financiamento. Além disso, durante a realização da pesquisa junto às empresas, percebeu-se que o conceito de APL, conforme já comentado, não é conhecido entre as próprias empresas do setor, pois suas ações não são difundidas.

Observou-se que poucas empresas fazem parte da governança e se beneficiam dos subsídios para expor e participar de feiras, como a Movelpar, que ocorre nos anos ímpares no Pavilhão Expoara, em Arapongas. O APL está restrito a um pequeno grupo de empresas que não se preocupa em desenvolver as relações de forma generalizada, para alavancar a difusão de conhecimentos na rede e incrementar a cooperação.

A governança, ainda que tenha sido elaborada como constructo e mensurada no modelo, é um dos elementos constitutivos do APL. É pela participação dos membros individuais nela que a gestão do conjunto de empresas se engajaria em ações coletivas, cooperativas, de compartilhamento. Tanto como instância de gestão supraorganizacional como ritual periódico de propostas e avaliação de resultados, que permitiria a emergência do senso coletivo indispensável para que os benefícios, tanto em tese quanto em evidências de casos reais, do APL pudessem ser alcançados. Ainda que não esgote o universo, a governança é parte responsável para ampliação e diversificação de relações sociais fundamentais para que o desenvolvimento econômico seja sustentável, conforme atestam Granovetter (1992) e Weber (1994). O histórico das relações entre atores sociais fortalece o comportamento reciprocamente referido num determinado campo organizacional e tem a probabilidade de repetição contínua.

Contudo, foi justamente nesse estabelecimento de uma rede de relações que os atores locais não obtiveram êxito, mesmo que racionalmente consigam perceber as vantagens da cooperação, em especial no que se refere a redução dos custos e visibilidade mercadológica. Cabe ressaltar que não existem relações sociais plenas no APL investigado, tampouco as de natureza política, não havendo relações específicas que são requisitos para o funcionamento do APL, tais como intercâmbio de tecnologia, ou disposição coletiva para capacitação de mão de obra. Pode-se resumir a natureza das relações que seriam necessárias da seguinte forma: diminuir e mudar decisões individuais sobre as próprias empresas, em favor de uma decisão coletiva que orientaria as ações do conjunto delas.

Em relação à competitividade do setor, constatou-se que o grau de inovação nas empresas do APL é diferenciado e não sistematizado, e os esforços inovativos estão mais concen- 
trados entre as médias e grandes empresas que representam apenas 12,2\% do total (Ipardes, 2006a). Foi possível elencar alguns problemas, que são discriminados no quadro 2.

Quadro 2

\section{Problemas que afetam a competividade do setor}

\begin{tabular}{|c|c|}
\hline Problemas & Principais consequências \\
\hline $\begin{array}{l}\text { Desconhecimento de técnicas modernas de gestão, por } \\
\text { exemplo, Kanban, PCP, redução do set up, CEP, entre outras }\end{array}$ & $\begin{array}{l}\text { A maioria dos empresários utiliza, como metodologia de custos, } \\
\text { métodos contábeis tradicionais }\end{array}$ \\
\hline Falta de adequação do Senai/Cetman à realidade do APL & $\begin{array}{l}\text { Falta de parcerias com institutos e centros de tecnologia no } \\
\text { exterior, subutilização da capacidade produtiva instalada, recur- } \\
\text { sos tecnológicos não consorciados entre as empresas, falta de } \\
\text { assessoria para a aquisição de tecnologia }\end{array}$ \\
\hline Predominância de administração familiar & Ausência de informações sobre o setor e de marketing do setor \\
\hline Produtos similares concentrados nos mesmos mercados & $\begin{array}{l}\text { Identidade do polo como de produtos populares (baixa qua- } \\
\text { lidade), baixo nível de investimento e/ou ausência de design, } \\
\text { ausência de pesquisas sobre o perfil da demanda do consumidor } \\
\text { e de sua capacidade de absorver inovações, transporte e monta- } \\
\text { gem inadequados do produto, assistência técnica deficiente, falta } \\
\text { de assessoria aos empresários para atuar no mercado externo, } \\
\text { carência de informação mercadológica }\end{array}$ \\
\hline $\begin{array}{l}\text { Dificuldades por parte dos empresários em procurar diferenciar } \\
\text { os produtos }\end{array}$ & $\begin{array}{l}\text { A maior parte da produção tem como destino as classes de } \\
\text { baixa renda e o produto tornou-se uma commodity }\end{array}$ \\
\hline
\end{tabular}

Fonte: Elaborado pelos autores.

Conjugados, esses fatores reunidos contribuem para uma baixa competitividade do setor, impondo uma margem pequena de lucro, reforçando o isolamento entre as empresas. Como essa é uma característica do setor, o isomorfismo competitivo atua no sentido de manter essa situação, ao reforçar esse comportamento entre as empresas.

Para que a competitividade se desenvolva, segundo Rodrigues (2003), é necessário que as empresas do APL incrementem seus processos produtivos por meio do compartilhamento dos meios de produção e de investimentos na busca por melhores tecnologias, e isso tem ocorrido somente de forma discreta no APL de Arapongas.

Sobre as políticas públicas, evidencia-se que, de acordo com os entrevistados, há uma falta de continuidade das ações de apoio ao setor após o poder público ter incentivado a criação do APL. Isso foi observado por alguns atores responsáveis pela coordenação do APL, que se sentem abandonados: ${ }^{2}$

\footnotetext{
${ }^{2}$ Observa-se que o entendimento dos entrevistados sobre as políticas públicas não reflete o entendimento dos autores. Apenas mostra que os empresários têm uma visão errônea sobre o que são políticas públicas e querem sempre obter vantagens no processo.
} 
O governo do Estado é muito fraco em relação ao APL, tem uma rede APL criada [...], mas não vejo grandes movimentos estruturais, vejo movimentos quando tem eventos. Na minha leitura isso não é uma coisa só do Paraná, é do Brasil. Ninguém liga para ações estruturais. [ENT-2]

Tem coisas que o governo federal poderia fazer e não está fazendo e nem ouvindo as nossas carências. Há um discurso do governo estadual de que apoia, mas na prática não se observa isso. [ENT-5]

Apesar dessa reclamação, observou-se que há políticas públicas que subsidiam o segmento industrial. De acordo com Souza (2006) e Frey (2000), as políticas públicas para APLs focam o desenvolvimento local e setorial de modo a contribuir efetivamente para a sustentabilidade das empresas e seu crescimento socioeconômico. Nesse sentido, alguns fatores do ambiente técnico podem ser elencados para justificar o crescimento contínuo do faturamento no setor moveleiro de Arapongas. Outras políticas públicas do governo federal para o setor industrial buscaram promover o crescimento da atividade econômica, convergiram positivamente para as de APL, resumidas, segundo a Abinee (2013), as seguintes medidas válidas para a indústria:

v Adequação das taxas de câmbio para patamares mais realistas (desvalorização média do real em relação ao dólar de aproximadamente 17\% em 2012, em relação a 2011);

- Redução da taxa juros, tanto por meio da redução da taxa Selic como pela atuação dos bancos estatais, que competiram com os privados praticando taxas mais baixas. A taxa Selic no final de 2011 que estava em 11\% ficou em 7,25\% no final de 2012;

v Lançamento do Programa Brasil Maior, em agosto de 2011, que estabeleceu uma Política Industrial com objetivos claros e métodos de gerenciamento, cujo escopo é a inovação e o fortalecimento das cadeias produtivas dos setores industriais;

v Redução dos encargos da folha de pagamento, que favoreceu a fabricação de produtos cuja receita corresponde a cerca de $40 \%$ do faturamento do setor;

、 Redução dos custos do financiamento ao investimento pelo BNDES, com o Programa de Sustentação do Investimento (PSI), que contempla a aquisição de máquinas e equipamentos, e cuja taxa de juros ficou em 2,5\% ao ano em 2012;

จ Redução do IPI para produtos da "linha branca", materiais de construção e móveis;

v Lançamento do Programa Minha Casa Melhor da Caixa Econômica Federal com financiamentos para aquisição de móveis e eletrodomésticos.

Por sua vez, observou-se que essas políticas macroeconômicas foram aproveitadas pelo Ministério da Indústria e Comércio, que concebeu acordo com as Secretarias Estaduais e o Sebrai nacional, que ficou responsável pela análise dos projetos e avaliação da qualificação 
dos mesmos, para avaliar quais empresas participantes dos APLs teriam acesso a crédito do BNDES, resultando em programa de influência da política pública nacional em âmbito local.

É digno de nota que tais políticas convergentes não estiveram presentes continuamente ao longo da implantação e do funcionamento do APL, uma vez reconhecido formalmente. Parte delas oscilou em termos de constância e recursos, outras desapareceram, com destaque para altas sucessivas da taxa Selic e a redução do IPI. Em adição, sem impacto no ambiente técnico, apenas facilitaram as condições econômicas, mas não possuem relação causal com o estabelecimento das relações sociais necessárias, aumento de confiança e ação coletiva e cooperativa inerentes à proposta do APL.

Todas essas ações foram positivas e contribuíram para manter o faturamento do setor moveleiro num nível de crescimento relativamente estável. Contudo, isso não significa dizer que houve melhoria da competitividade, ou seja, o crescimento econômico (estimado em termos de faturamento) foi determinado pela situação do mercado e pelas políticas públicas do governo federal que subsidiaram a indústria, e não por aquelas que foram objetos deste estudo, relacionadas com o APL.

O principal público-alvo das indústrias araponguenses é a classe de baixo poder aquisitivo, ou seja, classes C e D, representando cerca de $92 \%$ do consumo; os indivíduos de médio poder aquisitivo representam $7 \%$; já para a classe A representam apenas $1 \%$ do consumo desses móveis. Segundo um dos entrevistados:

O polo é de commodity, atingindo predominantemente classes C e D. Eles começaram a entender que essas classes também querem qualidade. A qualidade é uma coisa que está intrínseca no processo produtivo, mas eles não tratavam dessa forma. Achavam que essas classes só compravam móveis baratos. Agora eles estão se preocupando em agregar valor e com isso precisaram de financiamento para visitar e participar de feiras e fazer investimentos. Esse projeto Minha Casa Minha Vida da Caixa refletiu no mercado interno, só que com a alta do dólar, eles se voltaram para as exportações que não são para grandes países (são para África, Oriente Médio e Ásia). É um tipo de exportação que também é commodity e tem baixo valor agregado. Por outro lado, o mercado interno está desaquecido, pois o usuário não está comprando e isso se observa pelo número de indústrias que estão dando férias coletivas. Estavam em alta e agora estão dando uma freada. [ENT-2]

De acordo com outro entrevistado, isso pode ser explicado da seguinte forma:

O desaquecimento do setor... O móvel em si, não é tudo igual. Há o ouro de mercado quando está vendendo muito um tipo de móvel. Por exemplo, rack/estante vendeu muito, foram os que mais se destacaram e o que mais cresceu. Se pegar a curva $\mathrm{ABC}$, rack/estante foram rápidos, fizeram uma curva bastante em ascensão e essa curva entrou em declínio em 2012. Depois veio guarda-roupa junto com cozinha planejada e com menos intensidade, estofado. Isso foi depois da ressaca de 2008/2009. O mercado é bem por conta de acasos. O consumidor vai ver cozinha, sala, jogo de quarto e a fábrica não tem a todo tempo todos os tipos de produtos disponíveis. A 
linha branca também tem um apelo muito grande de consumo, assim como a linha marrom. O consumidor, às vezes, vai para trocar o sofá, mas chega lá e vê que ele não tem a televisão de LED e aí ele é pego por uma promoção e deixa o sofá pra depois que ele terminar de pagar a televisão. O móvel não tem tanto apelo de consumo. Segundo um estudo do Sebrae, o móvel no passado era o terceiro item de consumo. Primeiro era a casa própria, depois o carro, depois o móvel. Nós perdemos espaço para eletrodomésticos, celular, viagem de férias e previdência. Se não me engano a última vez que olhei, tínhamos caído para sétimo em desejo de consumo, perdendo até para cosméticos [...]. Só que as classes emergentes que não tinha móveis aqueceram o setor, principalmente de móveis populares. [ENT-4]

Um fator mercadológico que impõe margem de lucro pequena para as empresas moveleiras é a estrutura de mercado oligopolista dos principais fornecedores de matéria-prima para móveis; basicamente, são apenas sete fornecedores de aglomerados e MDF, que impõem cotas às fábricas de móveis. Além disso, os principais compradores - redes varejistas como Casas Bahia, Magazine Luiza, entre outras - também possuem grande poder de barganha sobre as empresas de móveis, pois ditam o design e o preço final de muitos dos móveis (Ipardes, 2006b). Assim, o setor de móveis é pressionado nos dois lados da cadeia. Essa pressão mercadológica afeta a competitividade e limita investimentos na infraestrutura fabril, principalmente para as MPEs; e talvez gere temeridade e insegurança para plena efetividade do APL, que envolve o aumento do poder de barganha diante dos fornecedores e grandes distribuidores, mas nem é garantia certa de negociações mais favoráveis, nem afasta o risco de perda de contratos. Ainda que não seja o propósito aqui abordar os conceitos recentes do institucionalismo na constituição dos sujeitos, parece razoável a hipótese de preferir uma condição já conhecida e que tem sido suficiente para a sobrevivência dos negócios, do que se mobilizar para outro modelo de gestão que tem potencial para maiores resultados, mas que exige confiança e relações sociais desenvolvidas. A postura individual dos empresários acabou por restringir fortemente o processo de consolidação do APL no tempo.

Por isso, a remuneração da mão de obra fica prejudicada, os que trabalham no setor possuem baixa qualificação. Segundo um dos entrevistados, o quadro geral de instrução dos empregados do setor não ultrapassa o segundo grau completo. Assim, os salários que o setor paga não são atrativos e isto provoca escassez de mão de obra qualificada e, consequentemente, a competitividade do setor. As condições do ambiente técnico estão pressionando o APL a desenvolver ações para amenizar a situação. Tais ações têm sido paliativas, uma vez que não há um amplo envolvimento das empresas do setor para se encontrarem as melhores soluções. Diante dessa estrutura mercadológica, é difícil melhorar a competitividade do setor, explicando por que a hipótese 1 foi rejeitada.

Quanto ao contexto relacional, o desenvolvimento das relações sociais foi investigado para explicar parte do fenômeno e ajudar a responder a pergunta de pesquisa. A situação do baixo desenvolvimento das relações sociais também foi citada por Leonello (2001:103), ao concluir que "as relações interfirmas para troca de informações no cluster de Arapongas são pouco densas [...]". O estudo constatou que a tendência à cooperação é maior entre as 
MPEs, enquanto "[...] as médias e grandes empresas não são sensíveis à cooperação". Um dos entrevistados mencionou que "com a formação do APL, aumentou a confiança, contudo ela é restrita aos participantes da governança".

Falta mais reunião do APL e mais participação, pois não existe confiança. Essa questão de mercado, do medo de dividir mercado, isso tinha que fortalecer, mas ainda existe essa cultura de que se você passar determinadas informações, você pode perder mercado [...] [ENT-1]

Percebe-se que as reuniões são menos frequentes e mais direcionadas para resolver problemas do setor e para colocar ações em prática, como a realização e a participação em feiras, do que para desenvolver relações sociais mais fortes e efetivas. A cooperação ocorre timidamente no APL, mas todos os entrevistados reconheceram que ela é importante para desenvolver o setor, tanto que as empresas procuram manter contatos com algumas empresas do APL, com quem têm mais confiança e reciprocidade, para realizar ações em conjunto e obter benefícios econômicos. Isso explica por que a hipótese 2 foi aceita e a 3, rejeitada.

Ou seja, as relações sociais entre os atores produzem os resultados, mas são restritas e geram externalidades positivas entre as empresas que as desenvolvem. Por outro lado, elas pouco afetam a situação do mercado, nem se constituem em feedback para as políticas públicas definidas nas esferas de governo, tornando-se pressões institucionais unilaterais.

\section{Conclusão}

Diante dos resultados observados e do que é estabelecido no sistema conceitual da teoria institucional, foi possível avaliar que o crescimento econômico do Polo Moveleiro de Arapongas é mantido pelas condições econômicas do ambiente técnico, no período observado pela pesquisa. Contudo, essas condições técnicas são necessárias, mas não suficientes para transitar e sustentar um desenvolvimento econômico baseado em ação coletiva, cooperação, compartilhamento, capaz de gerar inovação, tecnologias, redução de custos, visibilidade mercadológica, qualificação de mão de obra, aumento de renda dos trabalhadores, alcance de novos mercados, entre outros, que tanto o conceito quanto pesquisas empíricas sobre APL têm potencial para permitir, em oposição à competição isolada de empresas.

Conforme foi visto no caso em estudo, as relações sociais necessárias são pouco diversificadas e densas no APL de Móveis de Arapongas, ou seja, prejudicadas por uma postura mais competitiva individual em um ambiente de desconfiança; o crescimento do faturamento, no período considerado pela pesquisa, ocorreu por dinâmica própria da indústria no país pelas políticas públicas convergentes identificadas e pela situação do mercado, mas distintas daquelas que envolvem o modelo de APL. O objetivo deste trabalho foi alcançado, tendo como base a pergunta de pesquisa formulada acerca da efetividade das políticas públicas para o desenvolvimento local (até mesmo regional), por meio de APL. Diante dos dados, testes de hipóteses e análise qualitativa, é seguro afirmar que não houve a efetividade pretendida; mesmo se 
considerando como questão de grau, pode-se apenas dizer que é restrita, com êxito limitado, a não mais do que um quarto das empresas moveleiras de Arapongas.

Em termos do modelo de APL, o APL de Arapongas pode-se considerar no período analisado um caso de fracasso. $\mathrm{O}$ foco se deu sobre os atores locais e sua capacidade de produzirem novas relações sociais, ou alterarem algumas normas vigentes incompatíveis e, portanto, não versou sobre métodos, recursos e dedicação dos agentes indutores. Algumas menções, tanto nesta pesquisa quanto em outras (Jacometti, 2013; Castro, 2013), citam falhas no material de orientação, poucas reuniões coletivas e visitas in loco. Além disso, a falta de acompanhamento periódico pelos responsáveis pelo treinamento para dirimir dúvidas foi notória, apesar do esforço do Sebrae Nacional e de suas agências regionais. Em que pese essa menção, um maior êxito não pode ser atribuído a apenas um dos indutores, pois houve também menções quanto a dificuldades de liberação de crédito, via Banco do Brasil e BNDES. Assim, como já citado, as Secretarias de Estado foram pouco permeáveis em rever os cursos de ação, não tendo feedback representativo, muito além dos levantamentos puramente descritivos e classificatórios fornecidos pela Fiep no caso do Paraná. Por isso, essa questão merece ser investigada para averiguar o quanto a forma de condução e assistências desses atores indutores pode ter contribuído negativamente para o caso em pauta.

No âmbito total da pesquisa, outro APL investigado foi o de Tecnologia da Informação (TI) de Londrina, sujeito à mesma influência dos indutores, que constituiu governança própria, ampliou mercados e produziu inovações; ao contrário da governança do APL de Arapongas que se estruturou sob a influência do Sima. Como hipótese a ser testada em estudo futuro, talvez o fato de a maior parte dos empresários de TI naquela localidade ser egressa dos cursos de computação ou engenharia da Universidade Estadual de Londrina (UEL) tenha facilitado o estabelecimento das relações sociais relevantes para o APL, tanto pela formação semelhante quanto pela identidade que a universidade confere aos seus egressos, e até mesmo relações de amizades existentes antes da implantação do modelo.

Em retrospecto, os estudos que predominaram nos anos de 1970 e 1980 enfatizaram o caráter coercitivo das instituições, tornando comuns as críticas sobre a limitação da capacidade explicativa do institucionalismo organizacional, por se concentrar na homogeneidade dentro de um grupo de organizações e atores que inferem nas ações uns dos outros, e também nos mecanismos isomórficos. Contudo, aceitando-se a segunda ilustração, a língua, pode ser pleiteado que a heterogeneidade não está excluída, ao contrário, o locus da interação, seu contexto reage com força no sentido oposto, e se tornou mais comum nos estudos a partir dos anos de 1990.

Para efeito prático, a preocupação é explicar o sucesso de ações estratégicas coletivas, sua apropriação e ajustes à realidade imediata, visando ampliar o escopo de variáveis a serem consideradas para sua implementação. Isto vai além das justificativas a partir dos benefícios econômicos que podem ser obtidos, incluindo as condições comunitárias que reforçam a cooperação, a estrutura de governança, critérios de decisão conjunta e a participação de outras organizações locais relevantes. 
Adverte-se que este setor, no caso estudado de Arapongas (PR), devido aos produtos padronizados, de qualidade limitada, voltada para consumidores de classe C e D, com margem de lucro pequena e sem poder de barganha com os principais fornecedores e compradores, está propenso à crise em função do cenário econômico mais recente, com aumento dos juros, inflação, taxas negativas que reduzem o PIB, desemprego, fim dos benefícios fiscais e contração de renda. Sem pretender que essas menções sejam uma projeção fatalista inevitável, gradativamente, todas essas variáveis vêm se manifestando de forma visível desde 2013 até o momento.

Mesmo que sejam superadas em um horizonte de alguns anos, do ponto de vista prático, o esforço imediato para um APL mais efetivo tem potencial tanto para atenuar o impacto de condições econômicas adversas quanto para aproveitar oportunidades em condições mais favoráveis. Por fim, entre outras investigações que podem ser propostas, seria o levantamento de indicadores qualitativos e quantitativos de comparação entre APLs para explicar o sucesso ou o fracasso de diversos casos.

\section{Referências}

ABINEE. Associação Brasileira da Indústria Elétrica e Eletrônica. Desempenho setorial. 2013. Disponível em: <www.abinee.org.br/abinee/decon/decon15.htm>. Acesso em: 15 jul. 2013.

AGRESTI, Alan; FINLAY, Barbara. Métodos estatísticos para as ciências sociais. 4. ed. Porto Alegre: Penso, 2012.

ATLAS.TI. Qualitative data analysis. Release 6.2.27. Berlin, ATLAS.ti GmbH, 2012. Disponível em: $<$ www.atlasti.com>. Acesso em: 4 out. 2012.

BARDIN, Laurence. Análise de conteúdo. 5. ed. Lisboa: Edições 70, 2009.

BEVIR, Mark. Governance as theory, practice and dilemma. In: BEVIR, Mark (Ed.). The Sage handbook of governance. Londres: Sage Publications, 2011. Cap. 1, p. 1-16.

CARSTENS, Danielle D. S.; MACHADO-DA-SILVA, Clóvis L. Estratégia e estrutura de relacionamentos na rede de Empresas Alpha. In: ENCONTRO NACIONAL DOS PROGRAMAS DE PÓS-GRADUAÇÃO EM ADMINISTRAÇÃO, 30., 2006, Salvador. Anais... Rio de Janeiro: Anpad, 2006. p. 1-13.

CASSIOLATO, José E.; LASTRES, Helena M. M.; VARGAS, Marco A. Cooperação e competitividade de MPME: uma proposta de instrumentos financeiros voltados a arranjos locais. In: FÓRUM INTERAMERICANO DA MICROEMPRESA, 5., 2002, Rio de Janeiro. Anais... Washington: MIF/BID, 2002.

CASTRO, Marcos de. Contexto institucional de referência, governança de redes e processos de cooperação e competição: estudo em arranjos produtivos locais do Estado do Paraná. Tese (doutorado em administração) - Programa de Pós-graduação em Administração, Universidade Federal do Paraná, Curitiba, 2013.

CHAFFEE, Ellen E.; TIERNEY, William G. Collegiate culture and leadership strategies. Nova York: American Council on Education and Macmillan, 1988. 
D'AUNNO, Thomas; SUCCI, Melissa; ALEXANDER, Jeffrey A. The role of institutional and market forces in divergent organizational change. Administrative Science Quarterly, v. 45, n. 4, p. 679-703, 2000.

DAVIS, Gerald F.; DIEKMANN, Kristina A.; TINSLEY, Catherine H. The decline and fall of the conglomerate firm in the 1980s: the deinstitutionalization of an organizational form. American Sociological Review, v. 59, n. 4, p. 547-570, 1994.

DIMAGGIO, Paul J.; POWELL, Walter W. The iron cage revisited: institutional isomorphism and collective rationality in organizational fields. American Sociological Review, v. 48, n. 8, p. 147-160, 1983.

DOVER, Graham; LAWRENCE, Thomas B. A gap year for institutional theory: integrating the study of institutional work and participatory action research. Journal of Management Inquiry, v. 19, n. 4, p. 305-316, 2010.

ERBER, Fábio. Eficiência coletiva em arranjos produtivos locais: comentando o conceito. Nova Economia, v. 18, n. 1, p. 11-32, 2008.

FONSECA, Valéria S.; MACHADO-DA-SILVA, Clóvis L. Conversação entre abordagens da estratégia em organizações: escolha estratégica, cognição e instituição. Revista de Administração Contemporânea, v. 14, n. spe., p. 51-75, set. 2010.

FREY, Klaus. Políticas públicas: um debate conceitual e reflexões referentes à prática da análise de políticas públicas no Brasil. Planejamento e Políticas Públicas, v. 21, p. 211-259, 2000.

GONÇALVES, S. A. Mudança estratégia, esquemas interpretativos e contexto institucional: um estudo de caso longitudinal. Revista Eletrônica de Ciência Administrativa, v. 6, n. 2, p. 1-28, 2007.

GRANOVETTER, Mark. Economic institutions as social constructions: a framework for analysis. Acta Sociologica, v. 35, n. 1, p. 3-11, 1992.

GREENWOOD, Royston et al. (Ed.). Introduction. In: GREENWOOD, Royston et al. The Sage handbook of organizational institutionalism. Los Angeles: Sage, 2008. p. 1-46.

GUARIDO FILHO, Edson R.; MACHADO-DA-SILVA, Clóvis L. A influência dos valores ambientais e organizacionais sobre a aprendizagem organizacional na indústria alimentícia paranaense. Revista de Administração Contemporânea, v. 5, n. 2, p. 33-63, 2001.

HAIR JR., Joseph F. et al. Multivariate data analysis. 7. ed. Nova Jersey: Prentice Hall, 2010.

HAYEK, Friedrich A. von. Competition as a discovery procedure. In: HAYEK, Friedrich A. von. New studies in philosophy, politics, economics and the history of ideas. Londres: Routledge \& Kegan Paul, 1978. p. 179-190.

IBGE. Instituto Brasileiro de Geografia e Estatística. Estatísticas do cadastro central de empresas, 2009. Disponível em: <www.ibge.gov.br/home/estatistica/economia/cadastroempresa/2009/ default.shtm>. Acesso em: 25 jun. 2013.

IPARDES. Instituto Paranaense de Desenvolvimento Econômico e Social. APLs do estado do Paraná: arranjo produtivo local de móveis de Arapongas. Nota técnica. Curitiba: Secretaria de Estado do Planejamento e Coordenação Geral/Ipardes, 2006a. 
IPARDES. Instituto Paranaense de Desenvolvimento Econômico e Social. Arranjos produtivos locais do estado do Paraná: identificação, caracterização e construção de tipologia. Curitiba: Secretaria de Estado do Planejamento e Coordenação Geral/Ipardes, 2006b.

JACOMETTI, Márcio. Institutional work na conformação do conhecimento difundido em redes interorganizacionais: estudo de APLs no Estado do Paraná. Tese (doutorado em administração) — Programa de Pós-graduação em Administração, Universidade Federal do Paraná, Curitiba, 2013.

KRAATZ, Matthew S.; ZAJAC, Edward J. Exploring the limits of the new institutionalism: the causes and consequences of illegitimate organizational change. American Sociological Review, v. 61, n. 5, p. 812-836, 1996.

LA ROVERE, Renata L.; SHEHATA, Lucy D. Políticas de apoio a micro e pequenas empresas e desenvolvimento local: alguns pontos de reflexão. Revista Redes, v. 11, n. 3, p. 9-24, 2007.

LASTRES, Helena M. M.; CASSIOLATO, José E.; MACIEL, Maria L. Pequena empresa: cooperação e desenvolvimento local. Rio de Janeiro: Relume Damará, 2003.

LEONELLO, João C. Análise do cluster moveleiro de Arapongas-PR: condições, limites e possibilidades de desenvolvimento. Dissertação (mestrado) - Programa de Pós-Graduação em Economia, Universidade Federal de Santa Catarina, Florianópolis, 2001.

MACHADO-DA-SILVA, Clóvis L.; FERNANDES, Bruno H. R. Mudança ambiental e reorientação estratégica: estudo de caso em instituição bancária. Revista de Administração de Empresas, v. 38, n. 4, p. 46-56, 1998.

MACHADO-DA-SILVA, Clóvis L.; FONSECA, Valéria S. Competitividade organizacional: uma tentativa de reconstrução analítica. Revista de Administração Contemporânea, v. 14, n. spe., p. 33-49, set. 2010.

MACHADO-DA-SILVA, Clóvis L.; LIMA, Solange de B. Estratégia, fatores de competitividade e contexto de referência das organizações: uma análise arquetípica. Revista de Administração Contemporânea, v. 6, n. 3, p. 7-32, 2002.

MARQUIS, Christopher; GLYNN, Mary A.; DAVIS, Gerald F. Community isomorphism and corporate social action. Academy of Management Review, v. 32, n. 3, p. 925-945, 2007.

MARQUIS, Christopher; LOUNSBURRY, Michael; GREENWOOD, Royston. Introduction: community as an institutional order and a type or organizing. In: MARQUIS, Christopher; LOUNSBURY, Michael; GREENWOOD, Royston (Org.). Communities and organizations. Emerald Group Publishing Limited, 2011. p. ix-xxvii.

MARSHALL, Alfred. Principles of economics. 8. ed. Londres: Macmillan, 1925.

MARTINELLI, Dante P.; JOYAL, André. Desenvolvimento local e o papel das pequenas e médias empresas. Barueri: Manole, 2004.

MEYER, John W.; ROWAN, Brian. Institutionalized organizations: formal structure as myth and ceremony. American Journal of Sociology, v. 83, n. 2, p. 340-363, 1977.

NATH, Summer K. A reappraisal of welfare economics. Londres: Routledge \& Kegan Paul, 1969. 
OUTHWAITE, William; BOTTOMORE, Tom. Dicionário do pensamento social do século XX. Rio de Janeiro: Jorge Zahar, 1996.

PACI, Raffaele; USAI, Stefano. The role of specialisation and diversity externalities in the agglomeration of innovative activities. Revista Italiana degli Economisti, v. 5, n. 2, p. 237-268, 2000.

PETERS, B. G. Institutional theory. In: BEVIR, Mark (Ed.). The Sage handbook of governance. Londres: Sage Publications, 2011. p. 78-90.

PORTER, Michael E. Clusters and the new economics of competition. Harvard Business Review, v. 76, n. 6, p. 77-90, 1998.

PUTNAM, Robert D. Comunidade e democracia: a experiência da Itália moderna. 5. ed. Rio de Janeiro: Fundação Getulio Vargas, 2006.

REDESIST. Rede de Pesquisa em Sistemas e Arranjos Produtivos e Inovativos Locais. Análise do mapeamento e das políticas para arranjos produtivos locais no Sul, Sudeste e Centro-Oeste do Brasil. Relatório final: síntese dos resultados, conclusões e recomendações. Paraná, 2009.

ROCHA, Juliana D.; BURSZTYN, Marcel. Território, saberes locais e sustentabilidade: a busca do desenvolvimento via arranjos produtivos locais. In: ENCONTRO DA ASSOCIAÇÃO NACIONAL DE PÓS-GRADUAÇÃO E PESQUISA EM AMBIENTE E SOCIEDADE, 3., 2006, Brasília. Anais... Brasília: 2006. p. 1-16.

RODRIGUES, Andréia M. Cluster e competitividade: uma análise da concentração de micro e pequenas empresas de alimentos no município de Marília/SP. Tese (doutorado) — Escola de Engenharia de São Carlos, Universidade de São Paulo, São Carlos, 2003.

SAUSEN, Jorge O. et al. Gestão estratégica e inserção no processo de desenvolvimento local e regional: estratégias de intervenção na dinâmica do desenvolvimento econômico e social. Revista Gestão Organizacional, v. 7, n. 1, p. 95-111, 2014.

SCOTT, William R. Institutions and organizations: ideas and interests. 3. ed. Los Angeles: Sage, 2008.

SCOTT, William R. Organizations: rational, natural and open systems. 5. ed. Englewood Cliffs, New Jersey: Prentice Hall, 2002.

SCOTT, William R. The organization of environments: network, cultural, and historical elements. In: MEYER, John W.; SCOTT, William R. (Ed.). Organizational environments: ritual and rationality. Beverly Hills, CA: Sage, 1983. p. 155-175.

SEBRAE. Serviço Brasileiro de Apoio às Micro e Pequenas Empresas. Termos de referência para atuação do Sistema Sebrae em Arranjos Produtivos Locais. Brasília: Sebrae, 2003. Disponível em: <http://cppg.am.sebrae.com.br/apl/popup.htm>. Acesso em: 15 set. 2012.

SILVA, Christian L. et al. Políticas de desenvolvimento e descentralização do Paraná: um estudo sobre APL Cal e Calcário da RMC. Informe Gepec, v. 13, n. 2, p. 104-120, 2009.

SIMA. Sindicato das Indústrias de Móveis de Arapongas. Dados do setor, 2013. Disponível em: <www.sima.org.br/dadosdosetor.html>. Acesso em: 14 jan. 2013. 
SOUZA, Celina. Políticas públicas: uma revisão da literatura. Sociologias, v. 8, n. 16, p. 20-45, 2006. SPSS. Statistical Package for the Social Sciences ${ }^{\circledR}$ for Windows: base system user's guide \& professional statistics. Release 20.0. Ontario, IBM, 2011.

STAKE, Robert E. Case studies. In: DENZIN, Norman K.; LINCOLN, Yvonna S. (Ed.). Handbook of qualitative research. Londres: Sage, 2000. p. 435-454.

SUZIGAN, Wilson et al. Clusters ou sistemas locais de produção: mapeamento, tipologia e sugestões de políticas. Revista de Economia Política, v. 24, n. 4, p. 543-562, 2004.

TSEBELIS, G. Jogos ocultos. São Paulo: Edusp, 1998.

VASCONCELOS, Flávio C. de. A institucionalização das estratégias de negócios: o caso das start-ups na internet brasileira em uma perspectiva construtivista. Revista de Administração Contemporânea, v. 8, n. 2, p. 159-179, 2004.

VICARI, Flávio M. Uma proposta de roteiro para diagnóstico de clusters. Tese (doutorado) — Escola de Engenharia de São Carlos, Universidade de São Paulo, São Carlos, 2009.

WEBER, Max. Economia e sociedade: fundamentos da sociologia compreensiva. 3. ed. Brasília: UnB, 1994. v. 1.

YIN, Robert K. Estudo de caso: planejamento e métodos. 3. ed. Porto Alegre: Bookman, 2005.

Márcio Jacometti é diretor de Graduação e Educação Profissional da Universidade Tecnológica Federal do Paraná (UTFPR), Campus Cornélio Procópio, e doutor em administração pela Universidade Federal do Paraná (UFPR). E-mail: marcio.jacometti@gmail.com.

Marcos de Castro é professor adjunto do Departamento de Administração da Universidade Estadual do Centro-Oeste (Unicentro), Campus Guarapuava, e doutor em administração pela Universidade Federal do Paraná (UFPR). E-mail: marcosdecastroms@yahoo.com.br.

Sandro Aparecido Gonçalves é pesquisador do Instituto Brasileiro de Estudos e Pesquisas Sociais (Ibepes) e doutor em administração de empresas pela Escola de Administração de Empresas de São Paulo, Fundação Getulio Vargas (Eaesp/FGV). E-mail: sag2@uol.com.br.

Mayla Cristina Costa é professora adjunta do Departamento de Contabilidade da Universidade Federal do Paraná (UFPR) e doutora em administração pela Universidade Positivo (UP). E-mail: mayla.c.costa@ gmail.com. 